\title{
Prognosis of patients with acute myocardial infarction admitted to a coronary care unit I: Survival in hospital
}

\author{
A. H. KITCHIN AND S. J. POCOCK \\ From the Department of Medicine, University of Edinburgh, Western General Hospital; and \\ Medical Computing and Statistics Group, Edinburgh University Medical School
}

On a basis of history, clinical examination, and the electrocardiogram it was possible to identify groups of patients with acute myocardial infarction with good and bad prognoses as regards hospital survival. Individual adverse factors were age, previous history of ischaemic heart disease, anterior infarction, persistent sinus tachycardia, pulmonary crepitations, hypotension, and raised venous pressure. Multivariate analysis showed four factors remaining significant-age, tachycardia, hypotension, and pulmonary crepitations. As a result of treatment of cardiac arrest, hospital mortality, which would otherwise have been 20 per cent, was 17 per cent. Preceding unstable angina did not worsen the immediate prognosis.

With the opening of a coronary care unit in this district general hospital in 1966, a prospective study was planned of factors affecting survival of male patients with acute myocardial infarction. Patients were admitted to the study during the 3 years 1966 to 1969 and followed up subsequently for periods of up to $7 \frac{1}{2}$ years.

\section{Patients and methods}

Of 872 male patients under 70 years admitted to the

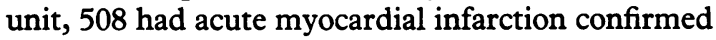
on a basis of two or more of the following criteria:(1) History of severe central chest pain lasting for more than 2 hours; (2) classical electrocardiographic abnormalities of recent infarction, or ST-T changes and increase in blood AST level; (3) left bundle-branch block and rise in blood AST level. Some patients who died early after admission were included on necropsy evidence only. The remainder had angina (143), other cardiovascular conditions (104), and miscellaneous respiratory, gastrointestinal, or musculoskeletal pains. The clinical features of patients included in the study are shown in Table 1.

Local general practitioners were approached and invited to seek admission directly to the unit of all patients suspected of having sustained a recent infarct. Doctors and nurses working in the unit used an agreed therapeutic schedule. Patient data were Received for publication 13 April 1977 recorded on specially designed proformata. Patients were treated in the unit for periods of 2 to 10 days (average 4). The estimated interval between the onset of infarction and admission to the unit was under 6 hours in 56 per cent, 6 to 24 hours in 28 per cent, and over 24 hours in 16 per cent. The mean time was 4 hours. Serial data recorded included heart rate, blood pressure, fluid balance, occurrence of arrhythmias, clinical observations of venous pressure, pulmonary crepitations, ausculatory findings in the heart, and complications.

\section{Results}

\section{(1) DEATHS IN HOSPITAL}

Sixty-four patients $(12.6 \%)$ died in the coronary care unit and a further $24(4.7 \%)$ during the remainder of their hospital stay. Total hospital deaths were therefore 88 or 17 per cent of patients admitted. Mortality was significantly related to several factors determined at the time of admission (Table 1). Age 60 or over, a low systolic blood pressure or sinus tachycardia maintained over 4 hours, increased venous pressure, and pulmonary crepitations were all associated with a higher mortality rate. A previous history of ischaemic heart disease also indicated a poorer hospital prognosis especially if the patient had had a previous infarct but gave no history of angina. The fact that heavy smokers had a significantly lower hospital mortality may be partly explained by the 
tendency for heavy smokers to be younger (69\% aged under 60 , versus $52 \%$ of the other patients).

A multivariate analysis, using linear logistic regression (Cox, 1970), was carried out in order to assess simultaneously the prognostic value of all these factors. This analysis shows that only 4 factors then have statistically significant regression coefficients; these are high pulse rate $(P<0.001)$, low blood pressure $(P<0.01)$, pulmonary crepitations $(P<0.02)$, and age over $60(P<0.01)$. It is of interest to note that the initial clinical assessment by the attending physician at the time of admission was a very reliable prognostic indicator with only 4 per cent of patients with 'good prognosis' dying in hospital compared with 67 per cent of those with 'poor prognosis'.

\section{Premonitory symptoms}

Unstable angina in the period 2 months to 1 day preceding infarction was reported by 37 per cent. This group of patients had hypotension significantly less commonly after infarction ( $46 \%$ versus $57 \%$; $\mathbf{P}<0.05)$ and more often gave a family history of ischaemic heart disease ( $37 \%$ versus $26 \% ; P<0.05$ ). They did not have a significantly higher mortality (Table 1; Fulton et al., 1972).

\section{Anterior myocardial infarction}

Patients with anterior infarction had a higher mortality than those with inferior infarction (Table 2). Anterior infarction was significantly associated with sinus tachycardia $(46 \%$ versus $33 \% ; \mathrm{P}<0.005)$ and presence of a third or fourth

Table 1 Hospital mortality and patient characteristics on admission

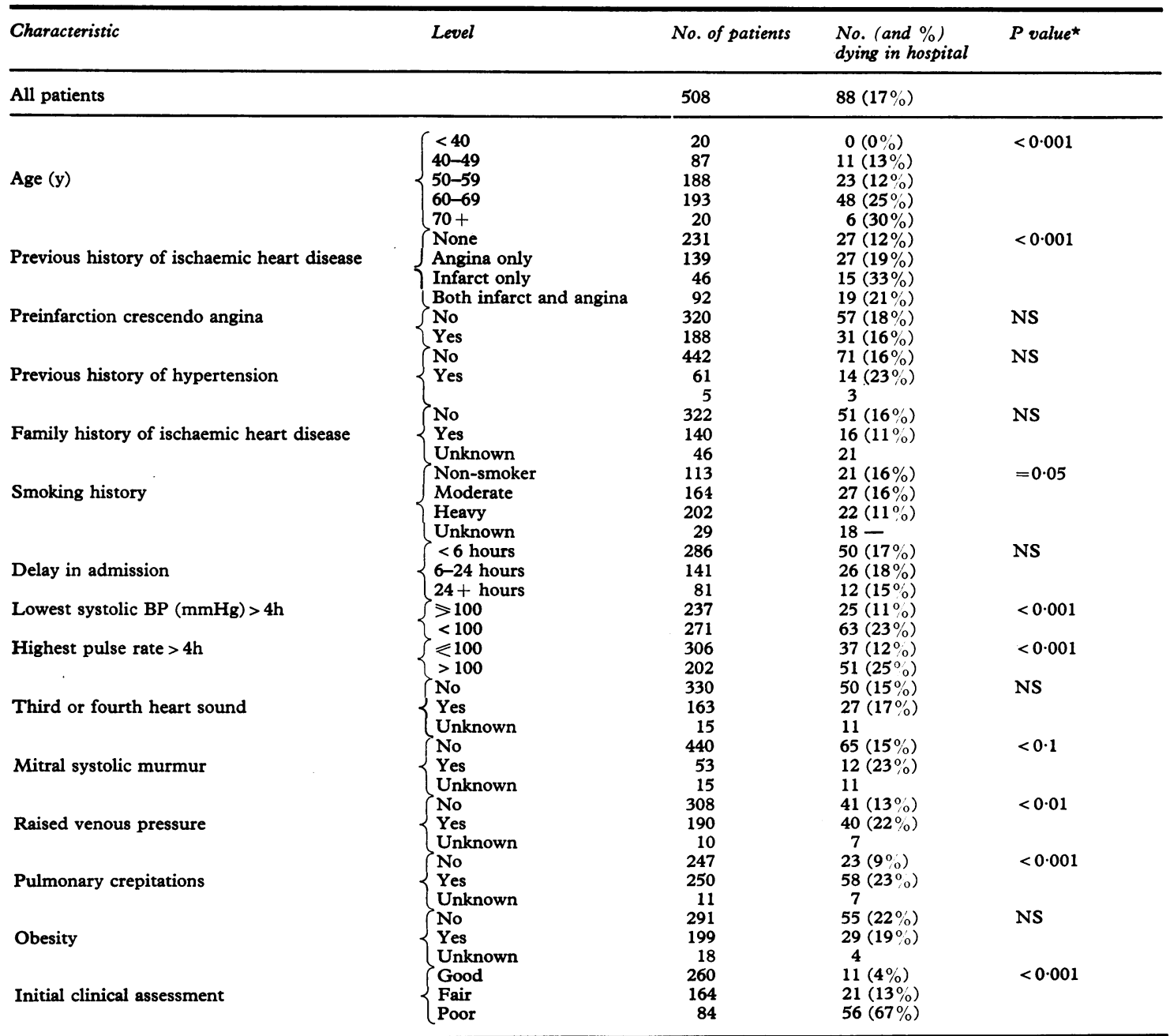

$\star$ Significance levels based on standard $\chi^{2}$ tests for comparison of percentages except for age when a test for trend in percentage was used. 
Table 2 Electrocardiographic abnormalities and hospital mortality

\begin{tabular}{|c|c|c|c|c|}
\hline & & No. of patients & $\begin{array}{l}\text { No. (and \%) } \\
\text { dying in hospital }\end{array}$ & Pvalue \\
\hline $\begin{array}{l}\text { Position } \\
\text { Q wave }\end{array}$ & $\left\{\begin{array}{l}\text { Anterior } \\
\text { Inferior } \\
\text { None/unknown } \\
\text { Yes } \\
\text { No } \\
\text { Unknown }\end{array}\right.$ & $\begin{array}{r}258 \\
220 \\
30 \\
347 \\
135 \\
26\end{array}$ & $\begin{array}{l}45(17 \%) \\
23(10 \%) \\
20 \\
55(16 \%) \\
14(10 \%) \\
19\end{array}$ & $\begin{array}{l}0.02 \\
0.08\end{array}$ \\
\hline
\end{tabular}

heart sound ( $38 \%$ versus $25 \% ; P<0.05)$ while inferior infarcts were associated with venous pressure increase $(45 \%$ versus $34 \% ; \mathrm{P}<0.05)$.

\section{Transmural infarction}

Presence of pathological $Q$ waves was associated with sinus tachycardia ( $46 \%$ versus $30 \% ; \mathrm{P}<0.005$ ) and arrhythmias $(42 \%$ versus $28 \% ; \mathrm{P}<0.005)$. It was commoner in inferior than in anterior infarcts $(50 \%$ versus $39 \% ; \mathbf{P}<0 \cdot 1)$. There was a marginally significant difference, however, as regards survival in hospital, compared with patients with intramural infarction (Table 2).

\section{(2) COURSE IN HOSPITAL}

The frequency of various clinical observations in patients in the coronary care unit is shown in Table 3.

\section{Arrhythmias}

Arrhythmias (excluding asystole) requiring treatment according to defined criteria occurred in 39 per cent of cases. The order of frequency was persistent ventricular extrasystoles, ventricular fibrillation, atrial fibrillation or flutter, atrioventricular block, sinus bradycardia, atrial tachycardia, and ventricular tachycardia. Arrhythmias were significantly commoner in patients with a previous infarct $(50 \%$ versus $36 \% ; \mathrm{P}<0.005)$ and in patients

\section{Table 3 Frequency of complications}

\begin{tabular}{lr}
\hline Frequency of complications & \\
\hline Persistent sinus tachycardia & $47 \%$ \\
Hypotension (<100 mmHg) & $47 \%$ \\
Cardiac failure-triple rhythm & $32 \%$ \\
$\quad$ venous presssure + & $37 \%$ \\
pulmonary oedema & $30 \%$ \\
Mitral systolic murmur & $10 \%$ \\
Arrhythmia requiring treatment & $39 \%$ \\
supraventricular & $16 \%$ \\
ventricular (not VF) & $15 \%$ \\
bradyarrhythmia & $7 \%$ \\
Cardiac arrest-85 cases of whom 25 survived & $17 \%$ \\
\hline
\end{tabular}

with pulmonary crepitations and hypotension (49\% versus $28 \% ; P<0.001)$. Atrioventricular block was commoner in inferior than in anterior infarcts $(8 \%$ versus $1 \% ; P<0.001)$. Sinus bradycardia did not predispose to ventricular arrhythmias or worsen prognosis (Table 1; Epstein et al., 1973).

\section{Cardiac arrest}

Cardiac arrest occurred in $85(17 \%)$ of cases, 38 from ventricular fibrillation and 47 from asystole. Only 2 patients with asystole were successfully resuscitated. Twenty-three patients with ventricular fibrillation were resuscitated, but of these only 12 survived to leave hospital. The majority of arrests occurred in patients with a combination of pulmonary crepitations and hypotension, and this group (145 in number) had a high hospital mortality of 30 per cent. Only 14 out of the 44 patients in this group who arrested were resuscitated, and none survived to leave hospital.

\section{Time of onset of symptoms}

Where admission to the coronary care unit was delayed beyond 6 hours after the onset of symptoms the frequency of cardiac arrest fell from 19 per cent to 4 per cent and of death in the coronary care unit from 14 per cent to 11 per cent. This presumably reflects the high early mortality from arrhythmia. In the few cases where admission was delayed beyond 24 hours the figures were 10 per cent and 7 per cent, respectively. However, there was no significant effect of delayed admission on overall hospital mortality (Table 1).

\section{AST levels}

These appeared to relate well to other measures of severity. Of 144 patients with AST greater than 100, 48 per cent had persisting sinus tachycardia, 62 per cent had hypotension, and 46 per cent had raised venous pressure compared with 36 per cent, 45 per cent, and 35 per cent, respectively, of 302 patients with lesser levels of AST $(P<0.1,0.001$, $0.05)$. Higher levels were commoner in transmural than in intramural infarcts $(36 \%$ versus $19 \%$; $P<0.005)$. 


\section{Discussion}

The present survey confirms the findings of others as regards the unfavourable effects on immediate mortality in the coronary care unit of increasing age and signs of heart failure or hypotension, and the neutral effects of previous high blood pressure, preinfarction crescendo angina, and obesity.

In some respects differences were found. Anterior infarcts were related to a higher mortality than inferior, confirming the finding of Norris et al. (1973) and at variance with those of Doscher and Poindexter (1950) and Beard et al. (1960). Norris et al. found a difference between transmural and intramural infarction, whereas Scheinman and Abbott (1973) did not; the present study gave only marginal support to the former. A past history of angina had an unfavourable effect in this study as in the series of Doscher and Poindexter (1950), Frank et al. (1973), and Norris et al. (1973), while Kannel and Feinleib (1972) and Chapman (1972) have found no such adverse effect. However, the present study showed that a previous infarct without angina led to an even worse prognosis.

It has to be said that the number of lives saved by electrical treatment of cardiac arrest was small $(3 \%)$ in relation to the total number of patients. Clearly, however, an additional unknown number of patients may have been saved in the coronary care unit by prophylactic treatment of arrhythmia and early treatment of cardiac failure.

It would be useful to identify categories of patients with myocardial infarction who have a good prognosis and who would not benefit significantly from treatment in a coronary care unit. In this series the number of hospital deaths together with successfully treated cardiac arrests which would have been fatal outside hospital represented 20 per cent of all cases. Review of the data shows that subgroups might have been identified on a basis of data available at the time of admission who proved to have a lower risk of cardiac arrest and death, the main factors being a younger age, absence of past history of angina or infarction, absence of pulmonary crepitations or hypotension, and a heart rate below 100 per minute. For example, of the 101 patients aged under 60 with no hypotension and no previous infarct only 7 per cent died or had a cardiac arrest in hospital.

The design of this study included an estimate of prognosis by the admitting registrar on the basis of history and examination. This proved a surprisingly accurate indication of the risk of dying from acute infarction.

\section{References}

Beard, O. W., Hipp, H. R., Robins, M., Taylor, J. S., Ebert, R. V., and Beran, L. G. (1960). Initial myocardial infarction among 503 veterans. American fournal of Medicine, 28, 871-883.

Chapman, B. L. (1972). Relation of cardiac complications to SGOT level in acute myocardial infarction. British Heart fournal, 34, 890-896.

Cox, D. R. (1970). The Analysis of Binary Data, pp. 87-91. Methuen, London.

Doscher, N., and Poindexter, C. A. (1950). Myocardial infarction without anticoagulent therapy. American fournal of Medicine, 8, 623-633.

Epstein, S. E., Goldstein, R. E., Redwood, D. R., Kent, K. M., and Smith, E. R. (1973). The early phase of acute myocardial infarction. Annals of Internal Medicine, 78, 918-936.

Frank, C. W., Weinblatt, E., and Shapiro, S. (1973). Angina pectoris in men; prognostic significance of selected medical factors. Circulation, 47, 509-517.

Fulton, M., Duncan, B., Lutz, W., Morrison, S. L., Donald, K. W., Kerr, F., Kirby, B. J., Julian, D. G., and Oliver, M. F. (1972). Natural history of unstable angina. Lancet, 1, 860-865.

Kannel, W. B., and Feinleib (1972). Natural history of angina pectoris in the Framingham study. American fournal of Cardiology, 29, 154-163.

Norris, R. M., Caughey, D. E., Deeming, L. W., Mercer, C. J., and Scott, P. J. (1973). Prognosis following acute myocardial infarction. New Zealand Medical fournal, 77, 12-18.

Scheinman, M. M., and Abbott, J. A. (1973). Clinical significance of transmural versus non-transmural electrocardiographic changes in patients with acute myocardial infarction. American fournal of Medicine, 55, 602-607.

Requests for reprints to Dr. A. H. Kitchin, Department of Medicine, Western General Hospital, Edinburgh EH4 2XU. 